\title{
Guignardia bidwellii causes leaf spot on Boston ivy in South Korea
}

\author{
Jin-Hyeuk Kwon ${ }^{1}$ • Okhee Choi $^{2}$ • Dong-Wan Kang ${ }^{1}$ • \\ Won-Il Kim ${ }^{3}$ • Jinwoo $\mathrm{Kim}^{2,4}$
}

Received: 6 December 2014 / Accepted: 15 May 2015 /Published online: 27 May 2015

(C) Australasian Plant Pathology Society Inc. 2015

\begin{abstract}
A severe outbreak of leaf spot was observed on Boston ivy (Parthenocissus tricuspidata) in Jinju, South Korea, during 2012 and 2013. DNA sequencing and phylogenetic analysis of the internal transcribed spacer rRNA gene region identified the isolates as Guignardia bidwellii, and Koch's postulates were supported by pathogenicity tests conducted on healthy plants. Based on mycological characteristics, pathogenicity tests, and molecular analyses, the causal fungus was confirmed to be G. bidwellii. To our knowledge, this is the first report of leaf spot caused by G. bidwellii on Boston ivy in South Korea.
\end{abstract}

Keywords Leaf spot · Guignardia bidwellii · Boston ivy · rDNA spacer sequence

Parthenocissus tricuspidata, also called both Boston ivy and grape ivy, is a flowering plant in the grape family (Vitaceae) native to Japan, Korea, and China (Gleason and Cronquist

Jin-Hyeuk Kwon and Okhee Choi contributed equally to this work.

Jinwoo Kim

jinwoo@gnu.ac.kr

1 Gyeongsangnam-do Agricultural Research and Extension Services, Jinju 660-360, South Korea

2 Division of Applied Life Science (BK21Plus), Gyeongsang National University, Jinju 660-701, South Korea

3 Microbial Safety Team, National Academy of Agricultural Science, RDA, Jeonju 560-550, South Korea

4 Institute of Agriculture \& Life Science, Gyeongsang National University, Jinju 660-701, South Korea
1991). It is widely grown as a climbing ornamental plant to cover the facades of masonry buildings.

A severe outbreak of leaf spot was observed on Boston ivy in Jinju, South Korea, during 2012 and 2013. Dark brown necrotic leaf spots were generally round, but occasionally angular and constrained by large leaf veins. Spots had black fruiting bodies (pycnidia) in the necrotic area. Leaves had numerous spots, resulted in defoliation, and elongated black lesions on the petiole eventually girdled these organs. Symptoms were similar to those reported previously for this species (Pscheidt and Ocamb 2014) (Fig. 1). Many small, black-colored pycnidia formed on the lesions (Fig. 2a). Pycnidia were dark brown, globose, and $90-150 \mu \mathrm{m}$ in diameter (Fig. 2b), while conidia were single-celled, hyaline, broadly ovoid, and 5-12×4-7 $\mu \mathrm{m}$ (Fig. 2c).

Five pycnidia within leaf lesions were removed and ground with a sterile scalpel in a $1.5-\mathrm{ml}$ microcentrifuge tube containing $0.1 \mathrm{ml}$ of sterile distilled water. The ground pycnidia were left to soak for $10 \mathrm{~min}$, after which $5 \mu \mathrm{l}$ of liquid suspension was spread onto oatmeal agar (OA). Mycelial tips were transferred to new $\mathrm{OA}$ at $25{ }^{\circ} \mathrm{C}$ for 15 days. Five fungal isolates were isolated from infected plant samples. One of the fungal isolates was deposited at the Korean Agricultural Culture Collection (KACC 47753), National Academy of Agricultural Science, Rural Development Administration, Jeonju, South Korea.

Molecular identification was done by PCR-mediated sequence analysis of the internal transcribed spacer (ITS) rRNA gene region (Kwon et al. 2014). The complete ITS rRNA gene region of the representative fungal isolate (KACC 47753) was amplified using the ITS1 and ITS4 primers (White et al. 1990). Total DNA was extracted using the Exgene ${ }^{\mathrm{TM}}$ Plant SV Mini Kit (GeneAll Biotechnology 


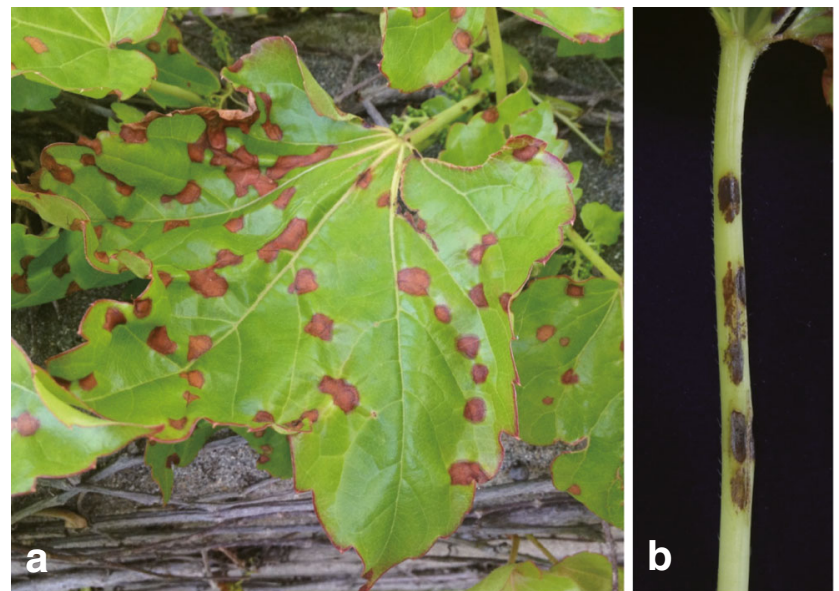

Fig. 1 Symptoms of leaf spot on Boston ivy plants caused by Guignardia bidwellii. a, Small, rounded lesions on leaves; $\mathbf{b}$, elongated lesions on the petiole

Co., Ltd., Seoul, South Korea), following the manufacturer's instructions. The polymerase chain reaction (PCR) mixture contained 5 units Taq polymerase (TaKaRa, Tokyo, Japan), $1 \times$ PCR buffer, $0.2 \mathrm{mM}$ of each dNTP, 5 pmol of each primer, and approximately $10 \mathrm{ng}$ fungal genomic DNA with the total volume adjusted to $50 \mu \mathrm{l}$ with sterile water. PCR was performed on a thermal cycler (PC 802; Astec, Fukuoka, Japan) according to the following conditions: $98^{\circ} \mathrm{C}$ for $2 \mathrm{~min}, 30 \mathrm{cy}$ cles of denaturation at $94{ }^{\circ} \mathrm{C}$ for $30 \mathrm{~s}$, annealing at $60^{\circ} \mathrm{C}$ for $30 \mathrm{~s}$, and extension at $72{ }^{\circ} \mathrm{C}$ for $30 \mathrm{~s}$, with a final extension at
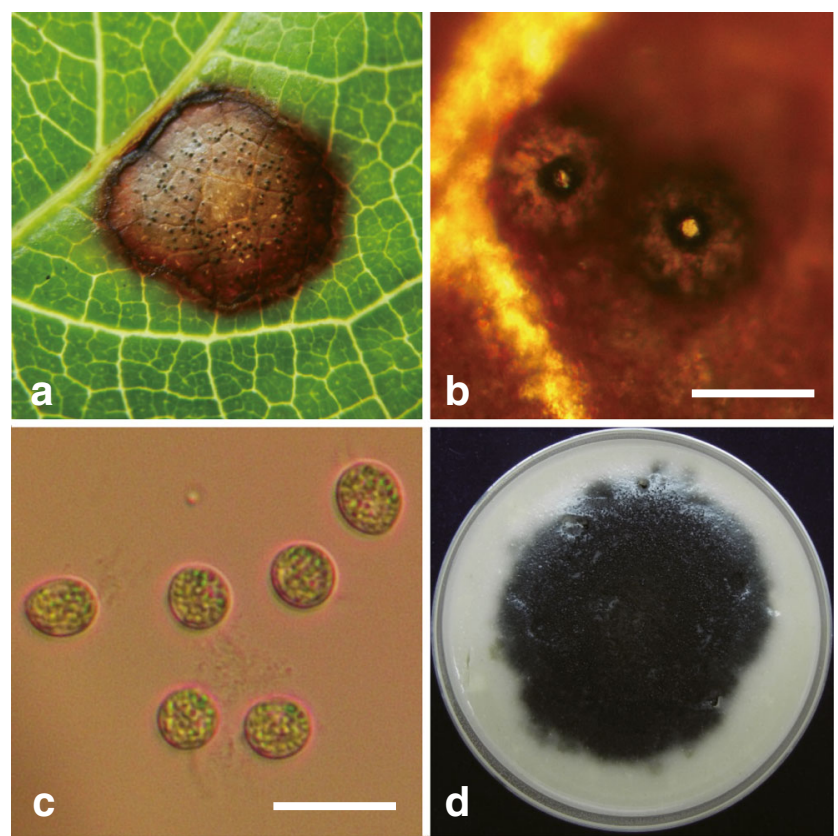

Fig. 2 Morphological characteristics of Guignardia bidwellii isolated from Boston ivy plant. a, Tiny, black pycnidia on a leaf lesion; $\mathbf{b}$, magnified pycnidia on a diseased lesion $($ bar $=100 \mu \mathrm{m})$; $\mathbf{c}$, conidia (bar $=10 \mu \mathrm{m}) ; \mathbf{d}$, pure culture of $G$. bidwellii on oatmeal agar 14 days postinoculation
$72{ }^{\circ} \mathrm{C}$ for $4 \mathrm{~min}$. Amplification products were separated by electrophoresis in $0.8 \%$ agarose gels. PCR products were purified using a QIAquick Gel Extraction Kit (Qiagen, Hilden, Germany) and cloned using the pGEM-T Easy Vector (Promega, Madison, WI, USA) according to the manufacturers' instructions. Plasmid DNA from white transformed Escherichia coli DH5 $\alpha$ colonies was extracted and purified using a plasmid extraction kit (GeneAll) and tested for the expected insert size (approximately $650 \mathrm{bp}$ ) by EcoRI (TaKaRa, Tokyo, Japan) digestion and visualization using gel electrophoresis and ethidium bromide staining. A resulting plasmid clone (pOR154) containing an insert of the expected size was isolated, and the insert was sequenced in both directions using the M13F and M13R primers at Macrogen Services (Daejeon, South Korea). Nucleotide sequences (643-bp) produced in this study were deposited in the GenBank database under accession number KP197058. The DNA sequences were later analyzed using the BLAST program (Altschul et al. 1990). The resulting sequence exactly matched the sequence of Guignardia bidwellii isolates MUCC0019, MUCC0037, and MUCC0120, associated with GenBank Accession nos. AB454268, AB454276, and AB454313, respectively, infecting Boston ivy plants in Japan (Motohashi et al. 2009; Wicht et al. 2012).

Phylogenetic analysis was performed using MEGA4.1 software (http://www.megasoftware.net/mega4/mega41. html) with the neighbor-joining method and the Tajima-Nei distance model (Tamura et al. 2007). Reference sequences of different Guignardia species were selected from GenBank, while the tree was rooted with Botryosphaeria dothidea as an outgroup (Sultan et al. 2011). The fungus isolated from a Boston ivy plant was placed within a clade comprising reference strains of G. bidwellii (Fig. 3).

Koch's postulates were fulfilled on detached Boston ivy leaves inoculated with conidial suspensions of the fungal isolate KACC 47753 . A conidial suspension $\left(10^{7}\right.$ conidia $\left./ \mathrm{ml}\right)$ from a single spore culture on PDA was inoculated onto five leaves, which were then stored in a plastic box $(29 \times 22 \times$ $15 \mathrm{~cm}$ ) containing moistened filter papers at $>90 \%$ relative humidity and $28^{\circ} \mathrm{C}$ for 10 days. Five leaves were inoculated with sterilized distilled water as a control. Symptoms appeared 10 days after inoculation, whereas controls were asymptomatic. The symptoms were identical to those of the naturally occurring disease. Morphological characteristics of the reisolated fungus from the inoculated leaves were the same as those from the original isolate, fulfilling Koch's postulates.

The objective of the current research was to isolate and identify the leaf spot fungus associated with recent occurrence of leaf spot on Boston ivy in South Korea. We focused on mycological characteristics, molecular identification using ITS rDNA sequencing, and pathogenicity assays on Boston ivy plants. Based on the mycological characteristics, molecular identification and pathogenicity, the fungus was identified 


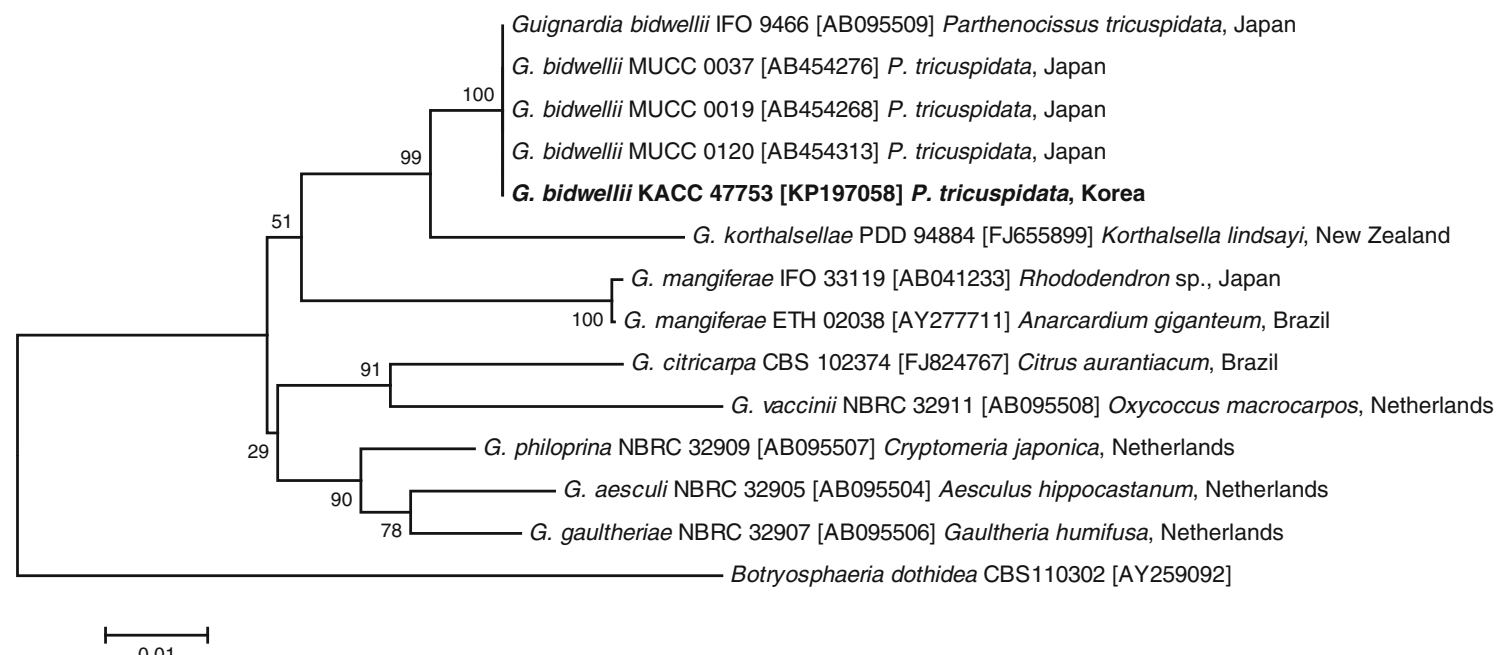

Fig. 3 Phylogenetic tree using internal transcribed spacer (ITS) sequences showing the closest known relatives of Guignardia bidwellii. DNA sequences from the NCBI nucleotide database were aligned using ClustalW, and a phylogenetic tree was constructed using the neighbor-

as Guignardia bidwellii. This is the first report of leaf spot on Boston ivy caused by this fungus in South Korea.

Acknowledgments Okhee Choi was supported by a scholarship from the BK21Plus Program, the Ministry of Education, Republic of Korea. This work was carried out with the support of "Cooperative Research Program for Agriculture Science \& Technology Development (Project No. PJ009192)" Rural Development Administration, Republic of Korea.

\section{References}

Altschul SF, Gish W, Miller W, Myers EW, Lipman DJ (1990) Basic local alignment search tool. J Mol Biol 215:403-410

Gleason HA, Cronquist A (1991) Manual of vascular plants of northeastern United States and adjacent Canada. New York Botanical Garden, Bronx

Kwon J-H, Kang D-W, Yoon H-S, Kwak Y-S, Kim J (2014) Rhizopus fruit rot caused by Rhizopus oryzae on strawberry. J Agric Life Sci 48:27-34 joining method and visualized with TreeView. Numbers above the branches indicate the bootstrap values. The culture isolated from Boston ivy plant in this study is in bold. The tree root was Botryosphaeria dothidea as an outgroup

Motohashi K, Inaba S, Anzai K, Takamatsu S, Nakashima C (2009) Phylogenetic analyses of Japanese species of Phyllosticta sensu stricto. Mycoscience 50:291-302

Pscheidt JW, Ocamb CM (2014) Pacific Northwest plant disease management handbook. Oregon State University. http://pnwhandbooks. org/plantdisease. Accessed 10 November 2014

Sultan A, Johnston PR, Park D, Robertson AW (2011) Two new pathogenic ascomycetes in Guignardia and Rosenscheldiella on New Zealand's pygmy mistletoes (Korthalsella: Viscaceae). Stud Mycol 68:237-247

Tamura K, Dudley J, Nei M, Kumar S (2007) MEGA4: molecular evolutionary genetics analysis (MEGA) software version 4.0. Mol Biol Evol 24:1596-1599

White TJ, Bruns T, Lee S, Taylor JW (1990) Amplification and direct sequencing of fungal ribosomal RNA genes for phylogenetics. In: Innis MA, Gelfand DH, Sninsky JJ, White TJ (eds) PCR protocols: a guide to methods and applications. Academic, San Diego, pp 315-322

Wicht B, Petrini O, Jermini M, Gessler C, Broggini GA (2012) Molecular, proteomic and morphological characterization of the ascomycete Guignardia bidwellii, agent of grape black rot: a polyphasic approach to fungal identification. Mycologia 104:1036-1045 